\title{
CONDECORAÇÕES DE GUERRA COMO INVESTIDURA DE BENS SIMBÓLICOS ÀS EX-ENFERMEIRAS FEBIANAS
}

\author{
War condecorations bestowed to former "febianas" nurses (nurses \\ of the brazilian expeditionary force ( F.E.B. acronym in portuguese) \\ as an investiture of symbolic value

\section{Condecoraciones de guerra como investidura de bienes simbólicos a las ex enfermeras febianas}

Tânia Cristina Franco Santos ${ }^{2}$

\begin{abstract}
RESUMO
Estudo histórico e social. Objetivos: descrever o ritual de concessão da Medalha de Campanha a algumas enfermeiras brasileiras que atuaram no Serviço de Saúde da Força Expedicionária Brasileira durante a Segunda Guerra Mundial e analisar os efeitos simbólicos desse ritual para o reconhecimento social de tais enfermeiras. 0 exame do corpus documental foi realizado mediante leitura e análise de uma fotografia, articulada aos documentos escritos e à bibliografia referente ao contexto em que foi produzida. Os achados foram iluminados pela Teoria do Mundo Social de Pierre Bourdieu. 0 estudo evidenciou que a presença de enfermeiras em um espaço misógino, para receber uma medalha de honra, consagrou sua aparição em um espaço público tradicionalmente ocupado por homens, contribuindo para a divulgação da imagem da enfermeira militar.
\end{abstract}

Palavras-chave: História da Enfermagem. Enfermagem Militar. Emblemas e Insígnias.

\begin{abstract}
The objectives of this social-historical study are to describe the ceremony involving the bestowment of the campaign medal of honor to nurses working in the health service of the Brazilian Expeditionary Force during World War II, and to analyze the effect of this symbolic ritual as a social recognition of these nurses. The examination of the documentary corpus was performed by the analysis of a photograph, and the related documents and bibliography that were produced in the same context in which the primary source was created. The findings were elucidated by Pierre Bourdieu 's World Social Theory. The study confirmed that the existence of these nurses within a misogynist society to receive a Medal of Honor consolidated their presence in a public arena occupied traditionally by men, contributing in this manner, to unveil and promote the image of the military nurses.
\end{abstract}

Keywords: History of Nursing. Military Nursing. Emblems and Insignia.

\section{Resumen}

Estudio histórico y social. Objetivos: Describir el ritual que envuelve otorgar la Medalla de la Campaña para algunas enfermeras brasileñas que actuaron en el Servicio de Salud de la Força Expedicionária Brasileira durante la Segunda Guerra Mundial, y analizar los efectos simbólicos de este ritual para el reconocimiento social de estas enfermeras. El análisis del corpus documentalfue realizado mediante la lectura y análisis de una fotografía, vinculada con los documentos escritos y la bibliografía referente al contexto en que la misma fue producida. Los hallazgos fueron impregnados por la Teoría del Mundo Social de Pierre Bourdieu. El estudio evidenció que la presencia de enfermeras en un espacio misógino, al recibir una medalla de honra, consagró su aparición en un espacio público tradicionalmente ocupados por hombres, contribuyendo para la divulgación de la imagen de la enfermera militar

Palabras clave: Historia de la Enfermería. Enfermería Militar. Emblemas e Insignias.

${ }^{1}$ Mestre e Doutorando em Enfermagem da Escola de Enfermagem Anna Nery (UFRJ). Membro da Diretoria Colegiada do Núcleo de Pesquisa de História da Enfermagem Brasileira (Nuphebras) gestão 2008-2009. Brasil. E-mail: alexbaroli@yahoo.com.br ${ }^{2}$ Professora Adjunta do Departamento de Enfermagem Fundamental da Escola de Enfermagem Anna Nery (UFRJ). Bolsista Capes de Estágio Pós-Doutoral (Escuela de Enfermería - Universidad de Valladolid - España). Membro Fundador do Nuphebras. Brasil. E-mail: taniacristinafsc@terra.com.br 


\section{INTRODUCÃO}

Nas palavras da antropóloga Martine Segalen, "rito ou ritual é um conjunto de atos formalizados, expressivos, portadores de uma dimensão simbólica". Assim, os rituais valem-se de um sistema de linguagens, comportamentos particulares e emblemas, que concedem bens simbólicos aos agentes de um determinado grupo, pois as demandas estéticas que envolvem os rituais são produtoras de efeitos simbólicos capazes de propiciar ao grupo a proclamação de uma identidade legítima de si. ${ }^{1}$

Ademais, os rituais instituem e consagram as diferenças, fazendo mover determinados grupos de uma esfera à outra, como do privado ao público, do mundano ao sagrado, pois instituir é consagrar, ou seja, sancionar ou santificar um estado de coisas, uma nova ordem estabelecida. Por isso, os rituais são responsáveis por reforçar os laços sociais entre os indivíduos e o grupo em que estão inseridos, produzindo como efeito uma espécie de reafirmação identitária de um grupo social.'

Sob tal perspectiva, o presente estudo tem como objeto os efeitos simbólicos do ritual de concessão da Medalha de Campanha pelo Exército às enfermeiras que atuaram no Serviço de Saúde da FEB (Força Expedicionária Brasileira) durante a Segunda Guerra Mundial. Esse ritual, realizado após o término da guerra, mais precisamente no dia 12 de outubro de 1945, teve como locus a Policlínica Militar, organização de saúde do Exército localizada no Rio de Janeiro. ${ }^{2}$

Neste estudo, partimos da premissa de que tais enfermeiras, ao receberem solenemente a Medalha de Campanha por suas atuações como militares na Segunda Guerra, em um espaço misógino, perceberam-se investidas de uma "identidade militar", uma vez que os ritos institucionais marcam solemente a passagem de uma linha simbólica, que instaura uma divisão fundamental da ordem social mediante seu efeito de consignação estatutária, pois aquele que é instituído sente-se compelido a ser e agir conforme sua nova identidade no espaço social.

Assim, a percepção dessa identidade militar pelas agora ex-enfermeiras da FEB, quando não mais usufruíam de suas patentes logo após o término da Segunda Guerra Mundial, ensejou que algumas delas vislumbrassem a possibilidade de lutar por suas posições de enfermeiras militares em um espaço que, antes da guerra, não admitia mulheres em seus quadros. ${ }^{3}$

Diante do exposto, traçamos os seguintes objetivos: descrever o ritual de concessão da Medalha de Campanha pelo Exército a algumas enfermeiras brasileiras que atuaram no Serviço de Saúde da Força Expedicionária Brasileira durante a Segunda Guerra Mundial, e analisar os efeitos simbólicos desse ritual para o reconhecimento social de tais enfermeiras.

\section{ABORDAGEM METODOLÓGICA E TEÓRICA}

Trata-se de um estudo de natureza histórica e social, que deriva do projeto de dissertação de mestrado intitulado "Signos do esquecimento: os efeitos simbólicos da participação das enfermeiras da Força Expedicionária Brasileira na Segunda Guerra Mundial (1943-1945)", concluído em maio de 2007 na Escola de Enfermagem Anna Nery, da Universidade Federal do Rio de Janeiro que, em observância às recomendações éticolegais propostas pelo Conselho Nacional de Saúde por meio da Resolução 196/96, recebeu parecer favorável pelo Comitê de Ética em Pesquisa da Escola de Enfermagem Anna Nery e Hospital-Escola São Francisco de Assis sob o número de protocolo 077/06 em 26/09/06.

As agentes que protagonizam este estudo representam uma fração das 67 enfermeiras que se apresentaram como voluntárias para tomarem parte do efetivo do Serviço de Saúde da FEB durante a Segunda Guerra, pela incorporação ao Exército Brasileiro, no posto de $2^{\circ}$ tenente da reserva. Aqui, elas são identificadas como "ex-Enfermeiras Febianas", pois, logo após o serviço prestado no Teatro de Operações da Itália, perderam sua patente, uma vez que, ao término da guerra na Europa Ocidental, todas foram desmobilizadas por força do Aviso Ministerial 217-185 (reservado), de 06/07/1945, deixando, por isso, de serem militares.

Como fonte primária preferencial, utilizamos um registro fotográfico da concessão da Medalha de Campanha a estas enfermeiras, que foi localizado no acervo pessoal da capitã enfermeira da reserva de $1^{a}$ classe Virgínia Maria de Niemeyer Portocarrero.

A fim de potencializarmos nossas competências nas leituras e releituras do texto icônico, buscamos estabelecer nexos com: o contexto político-social; a descrição do motivo, da data, do cenário, e dos agentes; a "habitalidade" do espaço; a representação do espaço; e a encenação que a foto encerrava.

Para tal, aproveitamos as ideias do historiador francês Jacques Le Goff quando considera a fotografia como "imagem/ documento", ou seja, como uma marca de uma materialidade passada, em que objetos, pessoas, lugares nos informam sobre determinados aspectos circunstanciais. Além disso, Le Goff também reconhece a fotografia como "imagem/monumento", como um símbolo àquilo que, no passado, a sociedade estabeleceu como imagem a ser perenizada para o futuro. Desse modo, é a fotografia portadora de uma informação e de conformação de uma determinada visão de mundo, aspectos esses que forneceram subsídios pontuais para 0 desenvolvimento do estudo. ${ }^{4}$

É importante destacar a colaboração das enfermeiras major reformada Elza Cansanção Medeiros e capitã da reserva de $1^{a}$ classe Virgínia Maria de Niemeyer Portocarrero no processo de descrição dos elementos elencados no espaço fotográfico e na identificação dos participantes do evento que a fotografia estampava. Cabe ressaltar que esta última fez-se presente no referido evento. 
A eleição da foto como fonte primária preferencial deve-se à constatação de que ela encerrou elementos simbólicos profícuos para a análise aqui proposta, mas que se fez também sustentada por meio da (re)leitura de outras fontes primárias, a saber: decreto, decreto-lei, aviso ministerial, estatuto, boletim interno, diplomas, biografias e folhas de alterações. Tais documentos foram majoritariamente encontrados no Arquivo Histórico do Exército e no arquivo da Policlínica Militar do Rio de Janeiro, ambos localizados no Centro do Rio de Janeiro.

Como fontes secundárias, utilizamos algumas obras bibliográficas que possuíssem um enquadramento temático

\section{RESULTADOS E DISCUSSÃO}

\section{O discurso da fotografia e seus efeitos na} consagração da enfermeira militar

Durante a Segunda Guerra Mundial (1939-1945), foi criado, por meio do Decreto-Lei 6.097, de 13/12/1943, o Quadro de Enfermeiras da Reserva do Exército, que representou o primeiro grupamento feminino de enfermagem militar oficialmente incorporado às fileiras das Forças Armadas na história do Brasil.

Ao todo foram 67 mulheres que, como voluntárias, alinharam-se à FEB, força combatente criada pelo Governo Vargas como parte do apoio prestado aos Países Aliados durante a Segunda Guerra Mundial e que contou com um efetivo de 25.334 cidadãos-soldados.

Nunca antes enfermeiras brasileiras foram convocadas de modo tão enfático a atuarem ao lado de uma tropa para um conflito de ordem mundial como fora a Segunda Guerra Mundial, agregando treinamento físico rigoroso, sentimento patriótico, prontidão, alerta e marcha, elementos que serviam para promover alguns ideais do Estado Novo, com a mobilização para uma guerra externa contra o nazi-fascismo, em nome de uma ideia de brasilidade. Entretanto, de maneira algo controversa, os líderes do regime defendiam a manutenção de seu caráter autoritário e ditatorial, em consonância com a corrente seguida pelos Países do Eixo contra os quais a FEB iria combater. ${ }^{6}$

Após a vitória dos Países Aliados e consequente término do conflito em meados de 1945 na Europa Ocidental, o presidente Getúlio Vargas, movido pela expectativa de que a nova visão de mundo daqueles que haviam tomado parte da FEB poderia ser incompatível com a de seu regime estadonovista, resolveu desmobilizar os expedicionários muitos dos quais ainda se encontravam no continente europeu. Esta ação foi resultado de uma preocupação com as possíveis consequências da chegada da FEB ao Brasil, vitoriosa e prestigiada, e as turbulentas repercussões políticas que poderia trazer ao já frágil regime. .-7 $^{-7}$ efetivo com o assunto desenvolvido, e que servissem para contextualizar historicamente os dados levantados.

A Teoria do Mundo Social de Pierre Bourdieu, que explora a configuração dos diferentes espaços sociais, e das hierarquias e lutas travadas entre os agentes situados no interior desses espaços, ${ }^{5}$ além dos estudos sobre rituais desenvolvidos por Martine Segalen e de rituais e emblemas, por Tânia Cristina Franco Santos, serviram de amparo para a análise aqui desenvolvida.

Não obstante, como parte de algumas poucas homenagens prestadas pelo Governo Vargas aos expedicionários, foram criadas, por meio do Decreto-Lei 16.821, de 13/10/1944, as Medalhas de Guerra, de Campanha e Cruz de Combate, com a finalidade de premiar aqueles que haviam participado da FEB. Embora usualmente desprezada na cultura "civil" brasileira, a concessão de medalhas é parte importante de um esforço de guerra, pois é a maneira de premiar os esforços individuais e coletivos e, também, meio de promover o moral das tropas. ${ }^{7}$

Em consulta às biografias e folhas de alterações de enfermeiras que participaram da FEB, verificamos que elas receberam as medalhas de Guerra e de Campanha. Pelo referido decreto-lei, o critério de concessão dessas medalhas que foram recebidas por elas era o seguinte: a Medalha de Guerra somente era concedida a oficiais da ativa ou da reserva [caso das enfermeiras] e a civis que tivessem prestado serviços relevantes para a campanha, de qualquer natureza, dentro ou fora do país, excluindo as praças. Já a Medalha de Campanha era distribuída a todos os militares, da ativa ou da reserva [caso das enfermeiras], que tomaram parte da campanha da FEB, sem nota desabonadora ${ }^{\mathrm{a}}$.

Do estudo que fizemos de relatos e publicações de enfermeiras e de outros membros da FEB sobre as condecorações recebidas, notamos que eles geralmente atribuem maior importância à Medalha de Campanha, posto que só receberam-na aqueles que realmente estiveram nos campos de batalha. É esta medalha que distingue, até hoje, o veterano da FEB que esteve no Teatro de Operações na Europa do "ex-combatente" não febiano que se manteve no Brasil empregado em ações de defesa. ${ }^{7}$ Assim, pelo seu valor simbólico é que destacamos a concessão da Medalha de Campanha neste estudo.

A fotografia a seguir estampa o ritual de entrega da referida medalha aos militares que participaram do esforço de guerra no Serviço de Saúde da FEB, entre os quais se fizeram presentes algumas enfermeiras. 


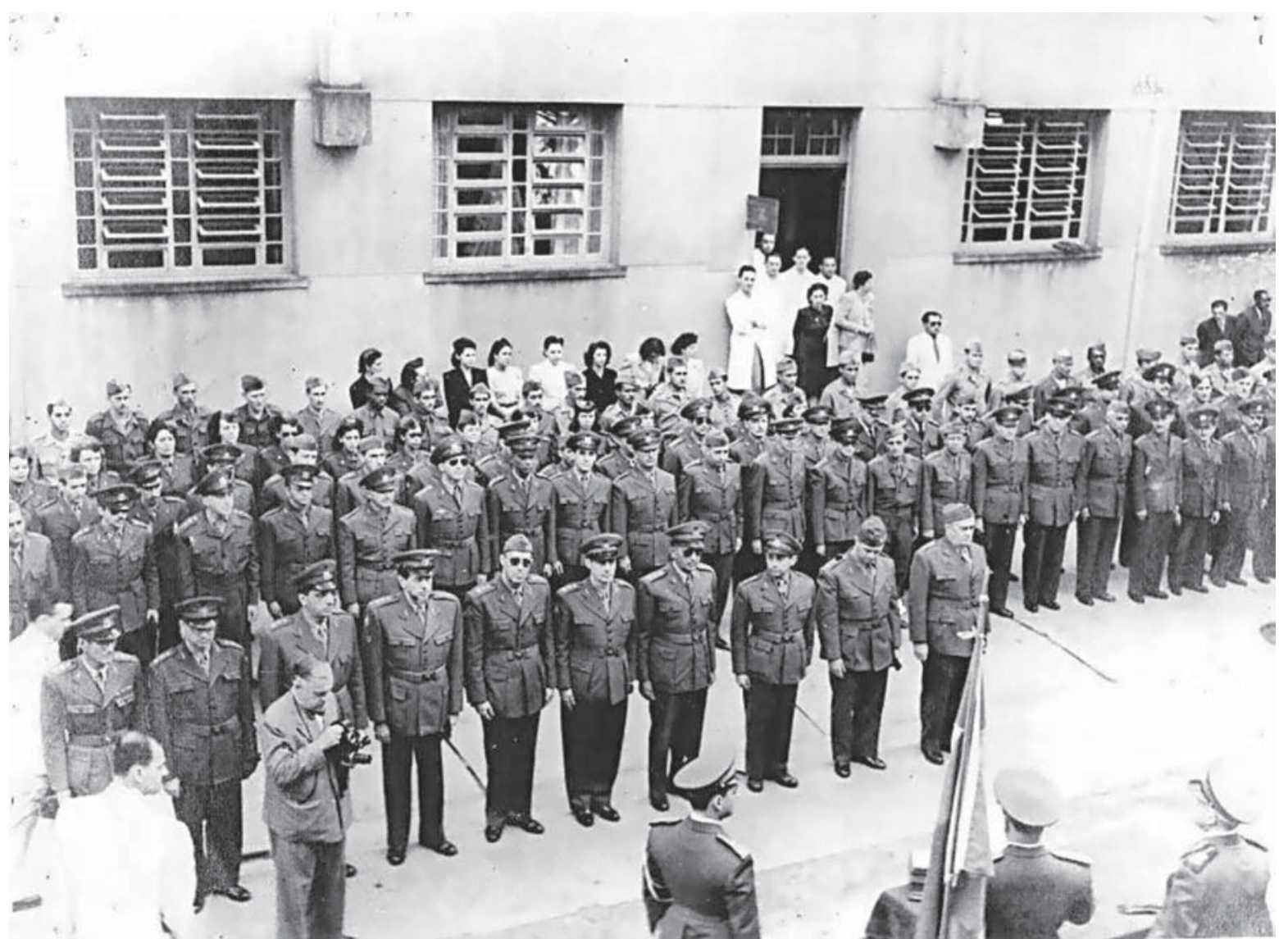

Fotografia 1: Solenidade de concessão da Medalha de Campanha na Policlínica Militar (acervo pessoal da Enfermeira Virgínia Maria de Niemeyer Portocarrero).

A cerimônia em tela foi realizada na área externa da Policlínica Militar, entre os seus dois prédios frontais no dia 12 de outubro de 1945. Esta organização militar de saúde do Exército Brasileiro, criada pelo presidente Nilo Peçanha em 1909 e inaugurada em 1910, acontecia na Rua Moncorvo Filho, no Centro do Rio de Janeiro, capital federal à época. Na ocasião, tal unidade estava sob comando do tenente-coronel médico Achilles Paulo Gallotti.?

Sobre os aspectos descritivos e técnicos da fotografia, temse um registro grupal, em aparente flagrante, composto em sua maioria por cidadãos fardados e outros em trajes civis, provavelmente realizado por um profissional, em preto e branco, de formato retangular $(23,2 \times 15,6 \mathrm{~cm})$ e em ótimo estado de conservação.

No grupamento em forma encontram-se perfilados aproximadamente 87 cidadãos fardados. À frente do grupamento está a bandeira nacional em um plano de destaque, ladeada por três autoridades militares, provavelmente todos médicos, dentre os quais estava o general Souza Ferreira (Diretor de Saúde do Exército na época).

Na primeira fila, destacados do restante do grupamento, observa-se a presença de 10 oficiais, em geral com postos de major ou capitão, todos provavelmente médicos. Na segunda fila há 20 oficiais, em geral com postos de capitão; na terceira fila, 21 oficiais, sendo a maioria composta por médicos. $\mathrm{Na}$ quarta e penúltima fila do grupamento encontram-se 13 exEnfermeiras Febianas fardadas. Da esquerda para a direita:
Zilda Nogueira Rodrigues, uma enfermeira não identificada, Ondina Miranda de Souza, Alice Neves Maia, Carmem Bebiano, Nicia de Moraes Sampaio, uma enfermeira não identificada, Olímpia de Araújo Camerino, Gema Imaculada Ottolograno, Virgínia Maria de Niemeyer Portocarrero, Altamira Pereira Valadares (provavelmente) e duas outras enfermeiras não identificadas. Na última fila, estavam presentes cerca de 24 graduados.

Atrás do dispositivo em forma, após a última fila, havia ainda oito ex-Enfermeiras Febianas não fardadas, totalizando 21 enfermeiras presentes. Da esquerda para a direita: uma enfermeira não identificada, Maria Luiza Vilela Henry, Neuza de Mello Gonçalves, Maria Belém Landi, Novembrina Augusta Cavallero, Silvia Pereira Marques e duas outras enfermeiras não identificadas.

Apesar de intrigante, não conseguimos identificar satisfatoriamente as motivações pelas quais as tais oito enfermeiras apresentaram-se àquele evento desprovidas de suas fardas. Outrossim, é sabido que o uniforme tem função adicional de padronizar as atitudes e o comportamento de quem o veste e, por conseguinte, de garantir a homogeneidade ao grupo. ${ }^{8}$ Contudo, ao que parece, esta condição não foi observada na conduta de todas as ex-Enfermeiras Febianas que participaram da solenidade em questão. Apesar disso, razoável parcela das enfermeiras homenageadas optou por fazer uso de seu fardamento. 
Observa-se, ainda, em uma escada que dava acesso a uma farmácia, a presença de duas mulheres e seis homens em trajes civis, além de dois homens também em trajes civis localizados mais à direita da porta. Sua disposição no arranjo fotográfico, bem como a indumentária utilizada, leva à suposição de que são servidores civis da Policlínica Militar e/ou convidados da cerimônia. Com relação ao número de pessoas presentes naquela solenidade, percebe-se que a presença feminina está minoritariamente representada.

0 fato de as enfermeiras estarem posicionadas junto ao grupamento em forma, ainda que nas últimas fileiras, evidencia uma estratégia de luta no sentido de evocar a sua pertença àquela corporação. Assim, essas agentes visaram sustentar a manutenção do habitus militar incorporado, pois, ao apresentarem-se fardadas, passaram a exprimir uma forma inculcada de dedicação ao alto comando e à instituição, expressando um sentimento de quase devoção ao cumprirem, diligentemente, o rito cerimonial. 0 que não deixou de ser uma estratégia para se fazerem presentes, de serem vistas como militares e, também, de dar continuidade à construção de uma idealização social sobre a figuração delas no campo do Exército.

0 posicionamento das pessoas constatado no espaço fotográfico revela uma distribuição hierárquica consoante com as posições ocupadas pelos agentes no campo do Exército, posições essas que são determinadas pelo volume de capital acumulado e que evidenciam "o ajustamento entre as estruturas objetivas e as estruturas interiorizadas por esses agentes sob a forma de um senso prático, que facilita a orientação nos domínios concernentes da existência social" ": $: 39$

Ademais, o espaço delimitado que foi ocupado pelas exEnfermeiras Febianas, embora na condição de homenageadas, evidencia o reconhecimento do valor de seu capital social naquele cenário, uma vez que o habitus, enquanto princípio da realidade social, faz com que cada um perceba os limites dos seus possíveis, mediante a interiorização das estruturas externas, ou seja, "interiorização no sentido de que se assume ou se aceita aquilo a que está destinado".":49

Portanto, a foto congela elementos que representam solenemente a diferenciação social que existia entre os presentes naquela cerimônia. À frente, "os" militares, médicos, seguidos de outros militares, também médicos em sua grande maioria, e, em um plano de menor destaque, "as" enfermeiras. Aliás, geralmente a divisão dos gêneros pode ser percebida em atividades produtivas e de interação social, como na área da saúde mais especificamente, retratando a histórica subordinação da enfermagem à medicina, em que a primeira representa uma profissão tradicionalmente feminina, enquanto a segunda é exercida principalmente por homens, ou simbolicamente desenhada pela inculcação dos valores masculinos. ${ }^{10}$

Subjacente à homenagem recebida pelas enfermeiras, esse ritual de entrega de medalhas consagra as diferenças existentes entre homens e mulheres, militares e civis, médicos e enfermeiras, uma vez que rituais institucionais tendem a "integrar as oposições propriamente sociais como se fossem propriedades de natureza natural".11:98

Além disso, a exposição do poder emanado das autoridades que comandavam aquela formatura renova o sentimento inculcado e instituído em posicionar essas mulheres como personagens sociais periféricas, pois, quanto mais acentuados são os símbolos da masculinidade (como eram e ainda são os eventos militares), mais as atividades tendem para o ritual e a codificação, e mais as mulheres são delas excluídas.

Portanto, embora a homenagem também fosse dirigida às enfermeiras que atuaram no Serviço de Saúde da FEB juntamente com os outros presentes, a disposição delas no espaço fotográfico não as colocou em relevo, a despeito de sua condição hierárquica e, portanto, de seu capital. Sendo assim, ao que parece, o lugar ocupado por cada um dos agentes na composição da formatura fora plasticamente prescrito do seguinte modo: a frente para os homens e a retaguarda às mulheres. Deste modo, essa suposta intenção (dominadora) contribuiu para a manutenção de posicionamentos derivados do poder institucional, via legítima reconhecida para tal.

Por outro lado, a medalha outorgada àquelas mulheres em um ritual institucional, concebido aqui como um "ritual de consagração", permitiu que elas capitalizassem alguns lucros simbólicos concernentes à sua participação na guerra, uma vez que os rituais institucionais têm efeito de consignação estatutária, os quais demarcam não apenas a passagem de um estado a outro, mas determinam a incorporação de um habitus consoante com as expectativas sociais ligadas àquela categoria, pois aquele que é instituído sente-se obrigado a estar de acordo com aquilo que dele se espera, à altura de sua função. A esse respeito, vale ressaltar que o verdadeiro milagre produzido pelos atos de instituição (consagração) reside, sem dúvida, no fato de que eles conseguem fazer crer aos indivíduos consagrados que eles possuem uma justificação para existir, ou melhor, que sua existência serve para alguma coisa. ${ }^{11}$

0 ritual, concebido como uma linguagem eficaz que atua na realidade social, necessita de um certo número de operações, gestos, palavras e objetos, e ainda, de uma espécie de transcendência. Outrossim, os rituais precisam estar apoiados em símbolos reconhecidos pela sociedade. Nesse sentido, para que o ritual de entrega de medalhas viesse a realizar-se como tal, foi preciso a adoção de algumas normas, posto que os rituais exigem geralmente uma forma, uma rotina, uma certa linha de conduta que dita aos agentes como eles devem agir diante daquilo que é sagrado. ${ }^{1}$

Para isso, faz-se necessário um comportamento ascético durante a preparação para o rito (restrições autoimpostas, como o dever patriótico inculcado de dar até a própria vida por amor à Pátria, além do dever de estar pronto para o serviço a qualquer momento, por exemplo), e também a utilização de símbolos (farda e distintivos militares) e a presença de alguns sacrifícios no momento do ritual (como o cansaço físico durante as formaturas militares, onde é necessária imobilidade em 
forma, e prontidão às vezes horas antes do evento e da chegada da autoridade; mas também o próprio comportamento ascético que exige a suspensão de algumas atividades cotidianas). ${ }^{1}$

Durante a solenidade foi proferido um discurso pelo general João Afonso de Souza Ferreira, responsável pela Diretoria de Saúde do Exército na época. Deste discurso, recortamos o seguinte trecho:

...E quanto a vós, gentis enfermeiras militares, que suave experiência representou para as nossas tropas em ação à presença da mulher brasileira, sob seu as-pecto por excelência tutelar, a lenir sofrimentos, a permitir a tantos que pudessem fitar, quiçá a hora derradeira, vossas faces transfiguradas para eles em outras faces longínquas, na visão esfaimada pela distância, para além dos mares, de mães, de irmãs, de noivas ou de esposas, que naqueles instantes supremos puderam ter em vós as suas representantes cre-denciadas, ao lado dos queridos entes! Como foi doce e refrigerante a vossa presença, como consolastes os que tombaram, como animastes os que continuaram a lutar. Graças vos sejam dadas pelos bens que dispen-sastes, pelos socorros que prestastes, pelo carinho que prodigalizastes (grifos nossos). ${ }^{2}$

A palavra e a sua circulação contam mais do que o espaço material. É ela que modela a esfera pública, que tece a opinião pública e que exerce, no caso do discurso proferido pelo Diretor de Saúde do Exército, o poder de enunciação que, nesta oportunidade, definiu o valor simbólico da presença das enfermeiras na guerra, enaltecendo seu significado tutelar de substituta dos papéis femininos, calcado no sentimento humanístico e em um comportamento gentil, dócil e carinhoso. Desta forma, percebe-se que, ao abordar aspectos sobre a participação daquelas enfermeiras no front, aquela autoridade militar, em seu discurso (legitimamente masculino), privilegiou 0 aspecto feminilizante em detrimento do profissional, o que promoveu e reforçou as assimetrias de gênero no campo do Exército. $^{12}$

Curiosamente, ao concluir seu discurso, o diretor de Saúde do Exército proferiu ainda as seguintes palavras:

Oficiais, enfermeiras, praças do Serviço de Saúde do Exército Brasileiro, sede orgulhosos de vossa Me-dalha de Campanha! Ostentai-a em vossos peitos generosos com a al-tivez de quem soube oferecer à Pátria querida o me-lhor de si mesmo, e lembrai-vos, ao vê-la, do que sofrestes na longínqua terra italiana, e fazei, ao tocá-la, o juramento sagrado de que sereis assim dignos e bravos como o fostes então, todas as vezes que for preciso defender, em qualquer campo de batalha, o pavilhão mil vezes sacrossanto e o nome mil vezes querido do nosso grande Brasil (grifo nosso).?
0 trecho acima reafirma a exclusão das ex-Enfermeiras Febianas enquanto participantes nos quadros de efetivo do Exército, uma vez que elas não foram referidas no chamamento final do discurso do general Souza Ferreira como "oficiais", condição angariada pelo grupo, que fora legalizada e legitimada durante a guerra pelo general Mascarenhas de Moraes (comandante da FEB), uma vez que a eficácia das palavras se exerce na medida em que o público-alvo reconhece quem a exerce como podendo exercê-la de direito, sujeitando-se a tal eficácia, como se estivesse contribuído para fundá-la por conta do reconhecimento que lhe concede. ${ }^{11}$

Nesse sentido, o general Souza Ferreira, detentor do poder simbólico naquela ocasião, "(des)nomeou-as oficialmente", o que violou simbolicamente o capital social atinente ao título militar (de oficiais) daquelas enfermeiras. Por esse discurso, então, formataram-se, demarcaram-se e reproduziram-se as diferenças hegemônicas entre o masculino e o feminino de modo tênue, porém poderoso, por meio de uma oratória que desconsiderou simbolicamente o título anteriormente conferido.

Além disso, a evocação dos atributos femininos demarcou a persistência dos papéis sexuais no cotidiano da enfermeira por meio do cuidado discreto, caridoso e abnegado, constituindo mulheres em estado de dependência simbólica, condicionadas pela expectativa masculina e, por extensão, subordinadas. ${ }^{13}$

Não obstante, o fato de aquelas enfermeiras terem recebido a Medalha de Campanha configurou-se como um elemento estratégico proficiente, que acabou por promover no círculo social do Exército uma maior visibilidade ao grupo, uma vez que, por meio desse rito institucional que foi respaldado pelas autoridades militares presentes, foram consagrados os feitos de guerra daquelas mulheres e trazido como produto um ganho simbólico que se mostrou socialmente naquele momento.

\section{CONSIDERACÕES FINAIS}

A análise do texto fotográfico referente à entrega da Medalha de Guerra àqueles que atuaram no Serviço de Saúde da FEB no Teatro de Operações, em seus aspectos visíveis, permitiu que este estudo chegasse a produzir resultados novos relativos às estratégias mobilizadas pelas ex-Enfermeiras Febianas inerentes à construção de uma imagem pública de enfermeira militar no campo social, ${ }^{14}$ resultados estes que, provavelmente, não seriam tão claros se tivéssemos utilizado apenas documentos escritos.

0 estudo evidenciou que a presença de enfermeiras, em um espaço misógino, para receber uma medalha de honra, conferiu visibilidade à enfermeira militar, consagrando sua aparição em um espaço público tradicionalmente ocupado por homens. Apesar da reafirmação dos papéis masculinos e femininos, o que se constitui como uma violência simbólica, tal homenagem ofereceu, simbolicamente, alguns elementos para a divulgação da imagem da enfermeira militar, pelo menos naquele recorte de tempo e espaço.

Assim, o uniforme, as medalhas, a bandeira nacional, o discurso do comando, aliado ao apelo patriótico e ao habitus 
incorporado mediante os esquemas de disciplina e hierarquia, serviram de elementos de inspiração e de apropriação do grupo, que, de certo, favoreceram a construção dessa identidade de enfermeira militar.

Evidenciamos, assim, o efeito simbólico que os rituais institucionais exercem, não apenas na promoção de reconhecimento no campo social, como também nas relações de poder que demarcam e subordinam a ocupação dos espaços sociais.

\section{REFERÊNCIAS}

1. Segalen M. Ritos e rituais contemporâneos. Rio de Janeiro (RJ): FGV; 2002.

2. Ministério da Guerra (BR). Diretoria Geral de Saúde do Exército. Boletim Interno ${ }^{0} 233$, de 12 de outubro de 1945. Publica discurso do diretor de Saúde do Exército em solenidade de entrega da Medalha de Campanha na Policlínica Militar.

3. Oliveira AB. Signos do esquecimento: os efeitos simbólicos da participação das enfermeiras da Força Expedicionária Brasileira que atuaram na Segunda Guerra Mundial: 1943-1945. [dissertação de mestrado]. Rio de Janeiro (RJ): Escola de Enfermagem Anna Nery / UFRJ; 2007.

4. Le Goff J. Documento/monumento. In: Enciclopédia Einaudi, 1. Lisboa (PO): Imprensa Nacional/Casa da Moeda; 1985.

5. Bourdieu P. 0 poder simbólico. $9^{\mathrm{a}}$ ed. Rio de Janeiro (RJ): Bertrand Brasil; 2006.

6. Oliveira AB, Santos TCF. Entre ganhos e perdas simbólicas: A (des)mobilização das enfermeiras que atuaram na Segunda Guerra Mundial. Esc Anna Nery Rev Enferm 2007 set; 11(3): 423-28.

7. Ferraz FCA. A guerra que não acabou: A reintegração social dos veteranos da Força Expedicionária Brasileira: 1945-2000. [tese de
Notamos ainda que praticamente existem poucos estudos que informam sobre como os rituais foram mobilizados na construção da imagem da enfermeira militar, e aproveitamos para alertar sobre a necessidade de se dar continuidade a esse tipo de abordagem, com a utilização de novos referenciais teóricos para construir novas versões sobre os rituais identitários da enfermagem militar.

doutorado]. São Paulo (SP): Faculdade de Filosofia, Letras e Ciências Humanas / USP; 2003.

8. Peres MAA, Barreira IA. Significado dos uniformes de enfermeira nos primórdios da enfermagem moderna. Esc Anna Nery Rev Enferm $2003 \mathrm{abr} ; 7(1): 25-38$.

9. Pinto L. Pierre Bourdieu e a teoria do mundo social. Rio de Janeiro (RJ): FGV; 2000.

10. Fonseca RMGS, organizador. Mulher e cidadania na nova ordem social. São Paulo (SP): NEMGE/USP; 1996.

11. Bourdieu P. A economia das trocas lingüísticas: o que falar quer dizer. $2^{a}$ ed. São Paulo (SP): Edusp; 1998.

12. Perrot M. Mulheres públicas. São Paulo (SP): UNESP; 1998.

13. Santos TCF, Barreira IE. A mulher e a enfermeira na nova ordem social do Estado Novo. Texto\&Contexto Enferm 2008 jul/set; 17(3): 587-93.

14. Santos TCF. Significado dos emblemas e rituais na formação da identidade da enfermeira brasileira: uma reflexão após oitenta anos. Esc Anna Nery Rev Enferm 2004 abr; 8 (1): 81-6.

\section{NOTA}

a - De acordo com o Estatuto dos Militares (1942), na estrutura hierárquica do Exército Brasileiro, os "postos" são destinados aos oficiais [marechal, general-de-divisão, general-de-brigada, coronel, tenente-coronel, major, capitão, $1^{\circ}$ tenente e $2^{\circ}$ tenente] e as "graduações" são facultadas às praças [aspirante-a-oficial, cadete, sargento ajudante, subtenente, $1^{\circ}$ sargento, $2^{\circ}$ sargento, $3^{\circ}$ sargento e cabo], enquanto que os soldados não possuem graduação na cadeia hierárquica. Para efeito da concessão da Medalha de Campanha, os oficias e praças ditos "da ativa" eram os considerados de carreira, pois já pertenciam ao efetivo do Exército antes da guerra. Os da reserva foram aqueles que se apresentaram como voluntários, e que foram desmobilizados após o término da guerra. 